\title{
Medical graduates becoming rural doctors: rural background versus extended rural placement
}

\section{Tyler R Clark BA, MA, Associate Lecturer, Office of Medical Education \\ Saul B Freedman FCSANZ, FACC, FESC Professor of Cardiology \\ Amanda J Croft BBus(AgrCom), Operations Manager ${ }^{2}$ \\ Hazel E Dalton \\ BSc(Hons), PhD, Research Administration Officer $^{2}$}

Georgina M Luscombe $\mathrm{BSc}$ (Hons), $\mathrm{PhD}$

Anthony M Brown MPH, FAFPHM, FAFOEM Associate Professor

David Triler MB BS, FRACP Professor of Medicine

Michael S Fromme MB BS, FAFPHM, FAFOEM Chair and Associate Dean

1 Sydney Medical School, University of Sydney, Sydney, NSW.

2 School of Rural Health University of Sydney, Sydney, NSW.

tyler.clark@ sydney.edu.au

MJA 2013; 199: 779-782 doi: 10.5694/mjal3.10036

Editorial p 722 Systematic review p 787

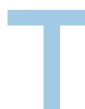
o encourage the development of a sustainable rural medical workforce, the Australian Government provides incentives for Australian medical schools to recruit students with a rural background and funds rural clinical schools to allow rural exposure via extended placements to students of all backgrounds.

Both recruitment of rural students and uptake of extended rural placements (ERPs) have been shown to be associated with choosing a rural career. ${ }^{1-4}$ We aimed to compare the apparent association of these two factors on students' expressed intentions to undertake rural internships and their acceptance of rural internships after finishing medical school.

The Medical Schools Outcomes Database (MSOD) and Longitudinal Tracking Project was established by the Deans of Australian and New Zealand medical schools in 2005..$^{5-6}$ For the MSOD, all Australian and New Zealand medical students are asked to complete a commencing medical students questionnaire on entry and an exit questionnaire on leaving their university courses. Among other things, the questionnaires cover career aspirations, including the types of setting in which students aspire to practise. The MSOD also follows medical students' postgraduate trajectories. Our comparison used longitudinal data from three cohorts of students in the Sydney Medical Program (SMP), the 4year graduate-entry program of the University of Sydney.

\section{Methods}

We analysed MSOD data ${ }^{5}$ for the student cohorts that commenced the SMP in 2005, 2006 and 2007 and completed it in 2008, 2009 and 2010, respectively. The variables studied were rural versus urban background, ERP (yes/no), preference for a rural or an urban internship, acceptance of a

\begin{abstract}
Objectives: To determine whether recruitment of rural students and uptake of extended rural placements are associated with students' expressed intentions to undertake rural internships and students' acceptance of rural internships after finishing medical school, and to compare any associations.
\end{abstract}

Design, setting and participants: Longitudinal study of three successive cohorts (commencing 2005, 2006, 2007) of medical students in the Sydney Medical Program (SMP), University of Sydney, New South Wales, using responses to self-administered questionnaires upon entry to and exit from the Sydney Medical School and data recorded in rolls.

Main outcome measures: Students' expressed intentions to undertake rural internships, and their acceptance of rural internships after finishing medical school.

Results: Data from 448 students were included. The proportion of students preferring a rural career dropped from 20.7\% (79/382) to $12.5 \%(54 / 433)$ between entry into and exit from the SMP. A total of 98 students took extended rural placements. Ultimately, 8.1\% (35/434) accepted a rural internship, although 14.5\% (60/415) had indicated a first preference for a rural post. Students who had undertaken an extended rural placement were more than three times as likely as those with rural backgrounds to express a first preference for a rural internship ( $\left.23.9 \% \vee 7.7 \% ; \chi^{2}=7.04 ; P=0.008\right)$ and more than twice as likely to accept a rural internship ( $\left.21.3 \% \vee 9.9 \% ; \chi^{2}=3.85 ; P=0.05\right)$.

Conclusion: For the three cohorts studied, rural clinical training through extended placements in rural clinical schools had a stronger association than rural background with a preference for, and acceptance of, rural internship.

rural or an urban intern position, and the preferred type of location of future practice.

We used $\chi^{2}$ analysis to assess associations between categorical variables and the McNemar test for repeated data. ${ }^{7}$ Where cell sizes were too small for valid analysis, the Fisher exact test (FET) $P$ is reported. $P<0.05$ was considered significant. Data were analysed using SPSS version 20.0 (SPSS Inc).

\section{Definitions and data sources}

An ERP was defined as a 32-week placement in the School of Rural Health (with clinical schools at Dubbo and Orange, in central-west New South Wales) or one of the university's two Departments of Rural Health (in Lismore, on the NSW North Coast, or Broken Hill, in far-west NSW) over the course of a single 37-week academic year. Students voluntarily applied to undertake an ERP and all students who applied were able to be accommodated. Data on whether individual students had undertaken an ERP were obtained from rolls kept by Sydney Medical School.
Rural or urban background was determined by the item in the commencing questionnaire asking students to nominate the type of location in which they had lived the longest within Australia. Locations were categorised according to the Rural, Remote and Metropolitan Areas (RRMA) classification ${ }^{8}$ and further grouped as urban or rural (Box 1). We used an answer of yes to "self-perception of rural background" as another measure of rural background.

Future practice location preferences were determined from responses in both the commencing and the exit questionnaires. Locations were mapped to RRMA categories and grouped as urban or rural (Box 1).

Internship first preferences were determined from the exit questionnaire. Students could indicate up to four hospital preferences for their intern year. We used the first preference. Hospital postcodes were categorised using the Australian Standard Geographical Classification Remoteness Area $^{9}$ and grouped as urban or rural (Box 1). 
Intern positions were determined from MSOD follow-up data and routine enquiries made by clinical schools regarding the locations of the internships taken up by their alumni.

Ethics approval was obtained from the University of Sydney Human Research Ethics Committee (Ref. No. 11436).

\section{Results}

Our analysis was confined to students who remained in their original entry cohort throughout the program and completed both the commencing and the exit questionnaires ("respondents"). We excluded students who left their original entry cohort and those who did not complete both questionnaires (Box 2). We followed a total of 448 students from the three cohorts (54.6\% of the total number of students enrolling in the 2005, 2006 and 2007 entry cohorts; $N=821$ ). While we did not have access to demographic variables for the cohorts overall, we note that the proportion of respondents who undertook an ERP $(98 / 448 ; 21.9 \%)$ was similar to the proportion overall (156/786; 19.8\%).

Of the 448 students followed, 426 (95.1\%) responded to the item on self-perception of rural background and 76 of these $(17.8 \%)$ considered themselves to be from a rural background. The item on the "location of longest residency within Australia" was answered by $415 / 448$ respondents $(92.6 \%)$, with 73 (17.6\%) having lived in a rural location for the longest part of their lives. The difference between classifying rural or urban background based on these two items was not significant (paired data; $n=397$; McNemar test $\left.\chi_{1}{ }^{2}=0.03 ; P=0.86\right)$. We based subsequent analyses on location of longest residency within Australia.

The characteristics, experience, preferences and internship locations of the 448 students in the three cohorts are summarised in Box 3. The proportion preferring a rural career dropped by more than one-third between entry into and exit from the program (from $20.7 \%$ to $12.5 \%$ ). ERPs were undertaken by $21.9 \%$ (98/448). Ultimately, $8.1 \%(35 / 434)$ of the students accepted a rural internship, although $14.5 \%(60 / 415)$ had indi-

1 Classifications used to categorise students' background locations and practice preferences as urban or rural

Rural, Remote and Metropolitan Areas (RRMA) Classification ${ }^{8} *$

Australian Standard Geographic Classification - Remoteness Area ${ }^{9 \dagger}$

\begin{tabular}{llcl} 
& & Urban $^{\ddagger}$ & \\
M1 & Capital city & RA1 & Major cities \\
M2 & Major urban centre & & \\
& & Rural $^{\ddagger}$ & \\
R1 & Regional city or large town & RA2 & Inner regional \\
& & RA3 & Outer regional \\
R2 & Smaller town & RA4 & Remote \\
R3 & Small community & RA5 & Very remote \\
\hline
\end{tabular}

* Used to categorise students' backgrounds and future practice preferences. $†$ Used to categorise internship first preferences and accepted placements. $¥$ Urban/rural distinction for RRMA categories is consistent with Gerber and Landau. ${ }^{10}$

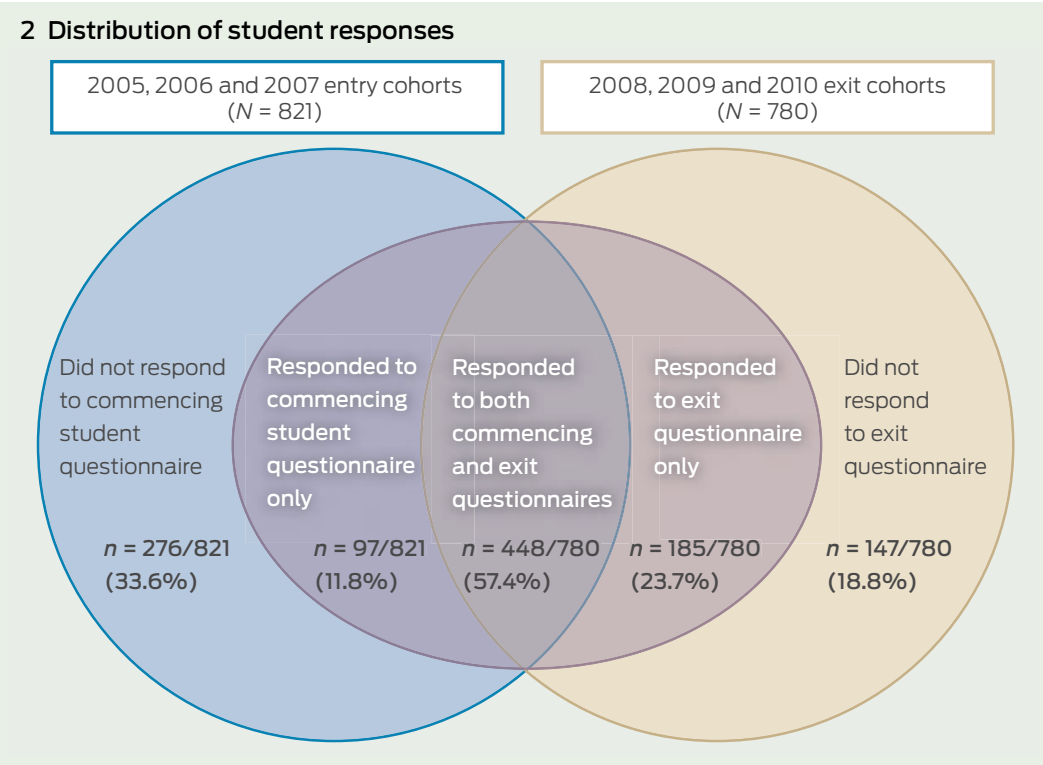

3 Characteristics, experience, preferences and internships of respondents from the 2005, 2006 and 2007 Sydney Medical School entry cohorts $(N=448)$

\begin{tabular}{llll} 
& $n *$ & Yes & No \\
\hline Rural background & 415 & $73(17.6 \%)$ & $342(82.4 \%)$ \\
Rural future practice preference (CMSQ) & 382 & $79(20.7 \%)$ & $303(79.3 \%)$ \\
Extended rural placement & $448^{\dagger}$ & $98(21.9 \%)$ & $350(78.1 \%)$ \\
Rural future practice preference (EQ) & 433 & $54(12.5 \%)$ & $379(87.5 \%)$ \\
Rural internship first preference & 415 & $60(14.5 \%)$ & $355(85.5 \%)$ \\
Accepted a rural internship & 434 & $35(8.1 \%)$ & $399(91.9 \%)$ \\
\hline
\end{tabular}

$\mathrm{CMSQ}=$ commencing medical students questionnaire. $\mathrm{EQ}=$ exit questionnaire.

*Number of respondents (students who remained in their original entry cohort throughout the Sydney Medical Program and completed both the commencing and the exit questionnaires) who answered the question. † Data obtained for all respondents from Sydney Medical School rolls.

cated in the exit questionnaire that they had a first preference for a rural post.

Students who had a rural background responded differently from those who undertook an ERP (Box 4 and Box 5). Compared with students from an urban background, students from a rural background were signifi- cantly more likely to prefer a rural future practice at the beginning of the program $\left(\chi^{2}=64.11 ; P<0.001\right)$ and at the end $\left(\chi^{2}=25.28 ; P<0.001\right)($ Box 4$)$. Significant differences were also found when students who undertook an ERP were compared with those who did not (Box 5) with regard to preference for rural future practice 


\begin{tabular}{|c|c|c|c|c|c|c|}
\hline & \multirow[b]{2}{*}{$n *$} & \multirow[b]{2}{*}{$\begin{array}{l}\text { Rural background, } \\
\text { no. }(\%)^{\dagger}(n=73)\end{array}$} & \multirow[b]{2}{*}{$\begin{array}{l}\text { Urban background } \\
\text { no. }(\%)^{\dagger}(n=342)\end{array}$} & \multirow[b]{2}{*}{ Total, ${ }^{\ddagger}$ no. (\%) } & \multicolumn{2}{|c|}{ Statistical comparison ${ }^{6}$} \\
\hline & & & & & $\chi^{2}$ & $P$ \\
\hline Rural future practice preference (CMSQ) & 368 & $37 / 63(58.7 \%)$ & $41 / 305(13.4 \%)$ & $78(21.2 \%)$ & 64.11 & $<0.001$ \\
\hline Extended rural placement (ERP) & 415 & $22 / 73(30.1 \%)$ & $72 / 342(21.1 \%)$ & $94(22.7 \%)$ & 2.83 & 0.092 \\
\hline Rural future practice preference (EQ) & 402 & $22 / 72(30.6 \%)$ & $29 / 330(8.8 \%)$ & $51(12.7 \%)$ & 25.28 & $<0.001$ \\
\hline Rural internship first preference & 387 & $5 / 65(7.7 \%)$ & $51 / 322(15.8 \%)$ & $56(14.5 \%)$ & 2.90 & 0.089 \\
\hline Accepted a rural internship & 402 & $7 / 71$ (9.9\%) & 24/331 (7.3\%) & $31(7.7 \%)$ & 0.56 & 0.455 \\
\hline
\end{tabular}

$\mathrm{CMSQ}=$ commencing medical students questionnaire. $\mathrm{ERP}=$ extended rural placement. EQ = exit questionnaire. * Total number of respondents who answered the question.

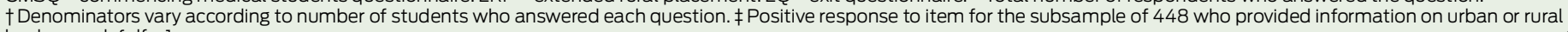
background. $\oint \mathrm{df}=1$.

\section{Respondent characteristics, experience, preferences and internships $(N=448)$, by extended rural placement $(E R P)(n=448)$}

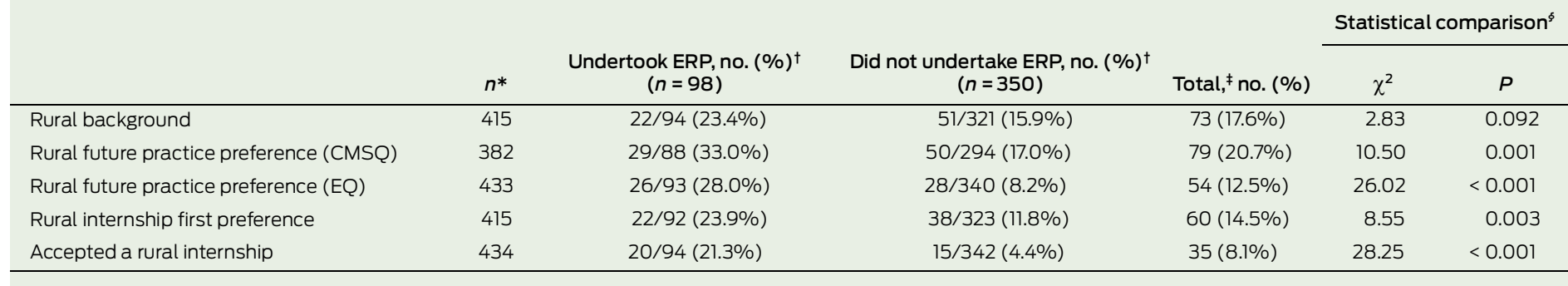

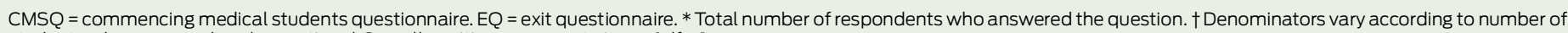
students who answered each question. $\ddagger$ Overall positive response to item. $\oint \mathrm{df}=1$.

at the beginning of the program $\left(\chi^{2}=10.50 ; P=0.001\right)$ and at the end $\left(\chi^{2}=26.02 ; \quad P<0.001\right)$. Respondents who undertook an ERP were more than three times as likely as those from rural backgrounds to express a first preference for a rural internship $\left(23.9 \%\right.$ v 7.7\%; $\left.\chi^{2}=7.04 ; P=0.008\right)$, and more than twice as likely to accept a rural internship $(21.3 \% \mathrm{v}$ 9.9\%; $\left.\chi^{2}=3.85 ; P=0.05\right)$.

Among respondents with a rural background (Box 4), 58.7\% (37/63) began the SMP with rural career intentions, but this proportion decreased to $30.6 \%(22 / 72)$ at the end of the program, an absolute reduction of $28 \%$. Among the group who undertook an ERP (Box 5), 33.0\% (29/88) expressed rural career intentions upon entry to the program, but this decreased to $28.0 \%$ (26/93) by the end. While the final proportions of students with rural career intentions were similar for both groups, the ERP group showed a smaller absolute decrease $(5 \%)$ between the start and the end of the program.

Rural backgrounds were overrepresented among the 98 students who undertook an ERP: the group comprised 22 of the 73 students with a rural background (30.1\%) and 72 of the 342 students who did not have a rural background (21.1\%) (Box 4). Among students with a rural background, there was a significant association between undertaking an ERP and rural internship preference and acceptance $(P=0.034$ and $P=0.021$, respectively [FET]; Box 6), however numbers were small. There were also highly significant differences between students from an urban background who undertook an ERP and those from an urban background who did not, in rural internship preference and acceptance $\left(\chi^{2}=5.43, P=0.020\right.$ and $\chi^{2}=$ 22.04, $P<0.001$, respectively; Box 6).

Of students who had a rural background and did an ERP, 4/21 (19.0\%) had a first preference for a rural internship, and 5/21 (23.8\%) accepted a rural internship. These proportions did not differ significantly for those students without a rural background who undertook an ERP, of whom 17/68 (25.0\%) had a first preference for a rural internship, and 14/69 (20.3\%) accepted a rural internship $(P>0.8$ for both comparisons), although numbers are too small to exclude a small difference.

\section{Discussion}

Our results clearly point to an association between undertaking an ERP and early postgraduate adoption of rural medical practice. Extended rural clinical placements appear to have a stronger association than that of rural background with students' preference for a rural internship and their acceptance of rural intern posts upon completion of their medical course. We observed that students with rural backgrounds were overrepresented among the students who undertook an ERP, so rural background may have contributed to rural internship preference and uptake in this group. The small numbers of students with a rural background who undertook an extended rural clinical placement preclude a definitive conclusion on whether the two attributes would be additive above the influence of undertaking an extended rural clinical placement. These findings echo the results of cross-sectional studies of student cohorts ${ }^{11,12}$ and retrospective studies of factors that influenced doctors to enter rural practice in Australia ${ }^{13}$ and Canada. ${ }^{14}$

The strength of our conclusions derives from the fact that we used longitudinal follow-up data for three successive cohorts of Australian medical students and obtained information on the end point of taking a rural 
6 Student characteristics, experience, preferences and internships $(N=448)$, by extended rural placement (ERP) split by rural background

\begin{tabular}{|c|c|c|c|c|c|c|}
\hline & \multirow[b]{2}{*}{$n^{*}$} & \multirow[b]{2}{*}{ Undertook ERP, no. (\%) ${ }^{\dagger}$} & \multirow[b]{2}{*}{ Did not undertake ERP, no. (\%) ${ }^{\dagger}$} & \multirow[b]{2}{*}{ Total, ${ }^{\ddagger}$ no. (\%) } & \multicolumn{2}{|c|}{ Statistical comparison ${ }^{s}$} \\
\hline & & & & & $\chi^{2}$ & $P$ \\
\hline Rural background students $(n=73)$ & & $(n=22)$ & $(n=51)$ & & & \\
\hline Rural future practice preference (CMSQ) & 63 & $15 / 21(71.4 \%)$ & $22 / 42(52.4 \%)$ & $37(58.7 \%)$ & 2.10 & 0.148 \\
\hline Rural future practice preference (EQ) & 72 & $10 / 21(47.6 \%)$ & $12 / 51(23.5 \%)$ & $22(30.6 \%)$ & 4.07 & 0.044 \\
\hline Rural internship first preference & 65 & $4 / 21(19.0 \%)$ & $1 / 44(2.3 \%)$ & $5(7.7 \%)$ & - & $0.034^{9}$ \\
\hline Accepted a rural internship & 71 & $5 / 21(23.8 \%)$ & $2 / 50(4.0 \%)$ & $7(9.9 \%)$ & - & $0.021^{9}$ \\
\hline Urban background students $(n=342)$ & & $(n=72)$ & $(n=270)$ & & & \\
\hline Rural future practice preference (CMSQ) & 305 & 14/63 (22.2\%) & $27 / 242(11.2 \%)$ & $41(13.4 \%)$ & 5.26 & 0.022 \\
\hline Rural future practice preference (EQ) & 330 & $15 / 69(21.7 \%)$ & $14 / 261(5.4 \%)$ & $29(8.8 \%)$ & 18.26 & $<0.001$ \\
\hline Rural internship first preference & 322 & $17 / 68(25.0 \%)$ & $34 / 254(13.4 \%)$ & $51(15.8 \%)$ & 5.43 & 0.020 \\
\hline Accepted a rural internship & 331 & $14 / 69(20.3 \%)$ & $10 / 262(3.8 \%)$ & $24(7.3 \%)$ & 22.04 & $<0.001$ \\
\hline
\end{tabular}

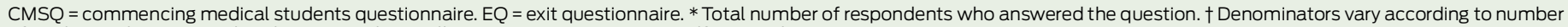
of students who answered each question. $\ddagger$ Overall positive response to item. $\oint \mathrm{df}=1$. १ Fisher exact test.

intern post. By following these cohorts, we were able to compare the apparent influence of an extended rural clinical training experience on students who had a rural background with its influence on those who did not. Our study thus demonstrated the value of the MSOD, which was set up at the time when the first cohort began their medical course. A weakness of our results is that they rely on the experience of the students of only one medical school. Also, the end point of rural internship is an important short-term outcome, but it will be interesting to observe the longer-term career choices of these students through longitudinal MSOD followup, or possibly through future linkage with Medical Board of Australia data.

Many possible reasons can be advanced to explain the association between extended rural clinical placements and both the preference for, and the acceptance of, rural internships. These include prior interest in rural medicine among students who choose to take an ERP; appreciation of the educational opportunities that are more likely to be available in rural settings than metropolitan settings, such as interprofessional learning; the smaller numbers of students in rural clinical schools, enabling more direct interaction between teaching staff and students; students' experience of a closer involvement with the health of rural communities than is possible with metropolitan communities; the broad appeal of the rural environment; and the quality of educational infrastructure that has resulted from consistent funding of rural clinical teaching facilities. The MSOD provides a vehicle for analysis of these possible reasons for the stimulating effect of extended rural placements.

In the meantime, our findings support the Australian Government's commitment to the funding of rural clinical schools and the provision of financial incentives for medical schools to ensure that at least $25 \%$ of each graduating cohort spends one academic year in a rural setting.

Acknowledgements: The University of Sydney School of Rural Health, where extended rural placements take place, is funded in part by the Commonwealth's Rural Clinical Training and Support program.

Competing interests: No relevant disclosures.

Received 8 Jan 2013, accepted 2 Oct 2013.

1 Henry JA, Edwards BJ, Crotty B. Why do medical graduates choose rural careers? Rural Remote Health 2009; 9: 1083.

2 Carter RG. The relation between personal characteristics of physicians and practice location in Manitoba. CMAJ 1987; 136: 366-368.

3 Rolfe IE, Pearson SA, O'Connell DL, Dickinson JA. Finding solutions to the rural doctor shortage: the roles of selection versus undergraduate medical education at Newcastle. Aust N Z J Med 1995; 25: 512-517.

4 McGrail MR, Humphreys JS, Joyce CM. Nature of association between rural background and practice location: a comparison of general practitioners and specialists. BMC Health Serv Res 2011; 11:63.
5 Medical Deans Australia and New Zealand. Medical schools outcomes database. www.medicaldeans.org.au/medical-s chools-outcomes-database (accessed Dec 2012).

6 Humphreys JS, Prideaux D, Beilby JJ, Glasgow NJ. From medical school to medical practice: a national tracking system to underpin planning for a sustainable medical workforce in Australasia. Med J Aust 2009; 191: 244-245.

7 Armitage P, Berry G, Matthews JNS. Statistical methods in medical research. 4th ed. Oxford: Blackwell Science Ltd, 2002.

8 Australian Institute of Health and Welfare. Rural, regional and remote health: a guide to remoteness classifications. Canberra: AlHW, 2004. (AlHW Cat. No. PHE 53; Rural Health Series No. 4.) http://www.aihw.gov.au/publicationdetail/?id=6442467589 (accessed Oct 2013).

9 Australian Bureau of Statistics. Australian Standard Geographical Classification (ASGC), July 2011. Canberra: ABS, 2009. (ABS Cat. No. 1216.0.) http://www.abs.gov.au/ausstats/ abs@.nsf/mf/1216.0 (accessed Nov 2012).

10 Gerber JP, Landau LI. Driving change in rural workforce planning: the medical schools outcomes database. Aust J Prim Health 2010; 16: 36-39.

11 Krahe LM, McColl AR, Pallant JF, et al. A multiuniversity study of which factors medical students consider when deciding to attend a rural clinical school in Australia. Rural Remote Health 2010; 10: 1477.

12 Stagg P, Greenhill J, Worley PS. A new model to understand the career choice and practice location decisions of medical graduates. Rural Remote Health 2009; 9: 1245.

13 Wilkinson D, Laven G, Pratt N, Beilby J. Impact of undergraduate and postgraduate rural training, and medical school entry criteria on rural practice among Australian general practitioners: national study of 2414 doctors. Med Educ 2003; 37 : 809-814.

14 Chan BT, Degani N, Crichton T, et al. Factors influencing family physicians to enter rural practice: does rural or urban background make a difference? Can Fam Physician 2005; 51: 1246-1247. 